\title{
El "gran mapa de la humanidad" y las Bellas Artes prehispánicas durante la Ilustración
}

Partiendo de algunas de las inquietudes que recorrieron el Siglo de las Luces, analizamos las aportaciones de criollos y españoles al conocimiento de las antigüedades y las Bellas Artes precolombinas entre finales del siglo XVIII y principios del XIX. Comprobaremos que durante este periodo las Bellas Artes empezaron a considerarse un reflejo de los logros de una sociedad. Devinieron por ello un elemento ineludible en la determinación del lugar que una civilización ocupaba en lo que contemporáneamente se denominó el "gran mapa de la humanidad".

PAlabras ClaVes: Historiografía Artística, Ilustración, Arte precolombino, Coleccionismo.

Starting by some of the concerns that were considered in the Age of the Enlightenment, we annalize Creoles and Spaniards' proposals to the knowledge of the PreColumbian antiquities and fine arts between the end of the $18^{\text {th }}$ century and the beginning of the $19^{\text {th }}$ century. We will verify that, during this period, fine arts started to be considered a reflection of a society's attaintments. As a result, they became an unavoidable component in the placing that a civilization occupied in what contemporaneously was called "the Great Map of Mankind".

Keywords: Artistic Historiography. Pre-Columbian Art. Collectionism.

\section{América en el "gran mapa de la humanidad" del siglo XVIII}

Entre los europeos del XVIII se difundió la creencia de haber logrado cartografiar, finalmente, la forma y los límites del mundo. Aunque ciertas regiones oceánicas y continentales seguían presentando desafíos al compás del geógrafo, fueron muchos los que afirmaron con orgullo los descubrimientos que se habían ido acumulando en los últimos años gracias a las nuevas expediciones de marinos y exploradores, permitiendo un conocimiento del globo como jamás se había tenido. Incluso un apasionado apologista de las consecuciones de los viajeros españoles durante los siglos 
XVI y XVII como Martín Fernández Navarrete, reconoció en su Relación del viage hecho por las goletas Sutil y Mexicana en el año de 1792 para reconocer el estrecho de Fuca (1802) los grandes progresos realizados en la centuria dieciochesca. En otra obra aparecida en estas décadas, en el prólogo del Atlas Elemental. Método nuevo, breve, fácil y demostrativo para aprender Geografía (1786) se subrayó que, contemporáneamente, los conocimientos geográficos habían conseguido alcanzar "tan alto grado de perfección" que el mundo entero era como una sola ciudad en la que sus habitantes podrían comunicarse con una "facilidad y seguridad de que los pasados no tuvieron ni aun idea". Tal vez fuese una exageración, pero el mundo, a los ojos de los hombres cultos del Siglo de las Luces, parecía más cercano y diáfano que nunca.

Si todo gran proceso necesita de unos héroes que lo encarnen, en el siglo XVIII no hubo duda de que el principal protagonista del renovado conocimiento del mundo era el almirante inglés James Cook. En una de las primeras biografías sobre el insigne marino, la Historia de la vida y viages del Capitan Jaime Cook de Andrew Kippis, aparecida en Londres en 1788 y traducida y editada en español en 1795, se afirmó que "antes de los viajes emprendidos en nuestros días, casi la mitad del globo estaba aún cubierta con un velo que ha rasgado el Capitán Cook". ${ }^{1}$ Según Kippis, gracias a sus tres grandes viajes por el Pacífico entre 1768 y 1779, Cook había aportado numerosos conocimientos, "desvaneciendo la ilusión de una tierra austral incógnita" y confirmando "la imposibilidad de hallar un paso septentrional del Océano Pacífico al Atlántico". Pero a los ojos de Kippis no tenían menos interés sus contribuciones al estudio del hombre y sus sociedades. Y es que los lejanos pueblos con los que Cook había entrado en contacto, sobre todo en las islas centrales del Pacífico, permitían observar muy distintas formas de civilización —al ser humano "en diferentes estados más o menos salvajes" en palabras de Kippis - ofreciendo "una materia muy interesante a las meditaciones y pesquisas del filósofo (ya que) se puede sacar de ellos una infinidad de hechos relevantes al hombre, a su perfectibilidad, a su defectuosidad, a sus virtudes, a sus vicios, a sus ocupaciones, a sus placeres, a su sensibilidad, a sus modales y a sus costumbres en cierto periodo de sociedad". Kippis destacó que "las curiosidades que se han traído de aquellas islas (del Pacífico) y que enriquecen el Museo

1 Kippis, Andrew: Historia de la vida y viages del Capitan Jaime Cook, Imprenta Real, Madrid, 1795, t. II, pág. 257. 
Británico... son una adquisición preciosa para la Inglaterra" porque suponían para su público una vivaz ilustración de las "meditaciones y pesquisas... relevantes al hombre" que podían encontrar en los, por otro lado, muy exitosos relatos de los viajes de Cook. ${ }^{2}$

En esta misma línea, Denis Diderot elogió las expediciones de otro de los grandes marinos del siglo, el francés Louis Antoine de Bouganville. Según el insigne ilustrado y uno de los principales animadores de la celebérrima Enciclopedia, los viajes de Bouganville por los mares del sur entre 1766 y 1769 a bordo de la fragata La Boudeuse y de la corbeta L'Etoile habían contribuido a una mayor "corrección en nuestros mapas geográficos" y, se destacó de nuevo, "un mejor conocimiento de nuestra vieja morada y de sus habitantes". ${ }^{3}$ Como es bien sabido, Bouganville no sólo se conformó con dar noticia en su Voyage autour du monde (1771) de los descubrimientos naturales y geográficos que había realizado y de las sociedades que había encontrado allende, sino que a su vuelta a París trajo consigo a un tahitiano llamado Aotourou. Desde su llegada fue una de las sensaciones en las más selectas tertulias de la capital ya que encarnaba las costumbres y las creencias de tan distantes y alejadas latitudes. Los parisinos, por fin, podían realizar aquel deseo expresado por Maupertius en su Lettre sur le progrés des sciences (1752), cuando afirmó que preferiría mantener una "hora de conversación" con un "primitivo" que "con la mente más lúcida de Europa". ${ }^{4}$

Es evidente que las razones - desinteresadas e ilustradas-- argüidas por Kippis, Diderot y por tantos otros destacados representantes de las Luces para enaltecer las contemporáneas expediciones transoceánicas no eran las únicas que las motivaron, palpitando tras ellas unas menos excelsas de naturaleza política y económica. Sabemos que estas expediciones fueron sufragadas por los gobiernos de las grandes potencias coloniales europeas en su pugna por la hegemonía mundial. Pero no por ello cabría juzgar las palabras de Kippis o Diderot como contradictorias o mera retórica. A muchos exploradores les movió una honesta apetencia de saber. Además, aumentar la esfera de influencia política y encontrar nuevas fuen-

2 Ibídem, t. II, pág. 260. Sobre el éxito de la literatura de viajes durante el siglo XVIII, véase: Pimentel, Juan: Testigos del mundo. Ciencia, literatura y viajes en la Ilustración, Marcial Pons, Madrid, 2003.

3 Bouganville, Louis Antoine de: Viaje a Tahití seguido de Suplemento al viaje de Bouganville o diálogo entre A y B por Denis Diderot, José J. de Olañeta, editor, Palma de Mallorca, 1999, pág. 69.

4 Citado en Bourguet, Maria Noëlle: "El explorador", en Vovelle, Michel: El hombre de la Ilustración, Alianza, Madrid, 1995, pág. 281. 
tes para el comercio internacional pasaba por conocer mejor el mundo, sus recursos y a sus moradores. Cuestión de globalización.

Sea como fuere, desearíamos subrayar que los exploradores dieciochescos que se lanzaron al conocimiento - y al dominio- del globo no sólo se preocuparon por reunir datos relativos a la geografía, a la geología o a la historia natural de los lugares que visitaron y en ocasiones descubrieron, sino de igual modo a la organización y usos de las distintas sociedades que los habitaban. También en este último punto los ilustrados del Viejo Continente creyeron haber realizado grandes avances. Tanto es así que Edmund Burke llegó a afirmar, en una frase célebre, que el mapa del mundo, pero también "the great map of mankind is unrolled at once". $\mathrm{Y}$ advirtamos que este conocimiento de las diversas sociedades que poblaban el globo fue altamente apreciado porque, aparte de completar el geográfico, abría una perspectiva inédita sobre la propia humanidad y su evolución. Si uno de los rasgos recurrentes del pensamiento ilustrado fue su activo interés por el análisis de la decadencia y el progreso de las sociedades y los saberes, imaginemos el enorme atractivo que suponía conocer las diferentes formas de vida del hombre. Se abría así, como decíamos, una ventana hacia la íntima indagación sobre el concepto mismo de civilización y las condiciones en las que se desarrollaba o decaía, a partir de la comparación de culturas diversas. Subrayemos que la mirada del XVIII, no obstante la exaltación del buen salvaje que algunos proclamaron, fue rotundamente etnocentrista. No hay duda de cual era la cultura que, según los ilustrados, ocupaba el lugar más privilegiado dentro de ese gran fresco de la humanidad recientemente desvelado. De hecho, el interés de las observaciones etnográficas de culturas distantes a las de la Metrópoli de partida residía, en gran parte, en que posibilitaba trazar la presunta evolución del hombre desde su estado más primitivo, o "más o menos salvaje", en palabras de Andrew Kippis, hasta el más civilizado, encarnado a su entender en las sociedades europeas continentales. En demasiadas ocasiones, el recorrido por el mundo que realizaron los europeos del siglo XVIII, ya fuese a bordo de barcos o con la ayuda de la muy exitosa literatura de viajes, acabó en una complaciente reafirmación que, entre otras consecuencias, legitimaba su política de control e intervención colonial. El propio Kippis afirmó que los viajes de Cook fueron conducidos por la Divina

5 Citado en Marshall, P.J. y Williams, Glyndwr: The Great Map of Mankind. British Perceptions of the World in the Age of Enlightenment, Dent, Londres, 1982, pág. 1. 
Providencia para llevar la civilización a territorios que hasta la fecha habían vivido de espaldas a ella.

Los españoles, no tan distantes como algunos han creído de las tensiones espirituales que dieron forma al Siglo de las Luces, participaron plenamente de estas inquietudes. Cuando el capitán Alejandro Malaspina elevó su plan de viaje por los mares del sur a Antonio Valdés, secretario de Estado y del Despacho Universal de Marina, destacó que gracias a expediciones de ingleses y franceses como la que deseaba emprender, "la Navegación, la Geografía y la Humanidad misma han hecho muy rápidos progresos". Y es que no sólo se había perfeccionado la navegación y "se ha enriquecido la Historia Natural con un número casi infinito de descubrimientos", sino que también "la Historia de la Sociedad humana se ha cimentado con investigaciones más generales". ${ }^{6}$ El gobierno no hizo oídos sordos a tales razones sino que las compartió, sufragando los gastos de su expedición. Pero la llamada expedición Malaspina, que se extendió entre julio de 1789 y septiembre de 1794 recorriendo amplias zonas del Pacífico, no fue ni mucho menos el único viaje trasatlántico organizado por la Corona española en este periodo. Durante toda la segunda mitad del siglo el gobierno español apoyó distintas expediciones científicas que tuvieron como objetivo preferente América. ${ }^{7}$ Un hecho en absoluto casual si tenemos en cuenta los decisivos intereses españoles en la zona. Como en el caso de Inglaterra y Francia, las otras dos grandes potencias coloniales, sus intereses prioritarios fueron de naturaleza geográfica, botánica e hidrográfica. Aspiraban a conocer con exactitud los recursos naturales que las colonias ofrecían y a determinar las mejores rutas comerciales, el estado de las costas, los puertos y sus defensas. Pero aun así, sus protagonistas -en su mayoría marinos, botánicos o geólogos formados en la Metrópoli- no dejaron de prestar atención a la vida de los hombres, y de manera especial a las formas de civilización más ajenas a la propia, es decir, a las sociedades indígenas, tanto a las modernas como a las antiguas. Pretendían no sólo determinar su grado de integración -o sometimiento- en el sistema imperial, sino también enriquecer, utilicemos las palabras del propio Malaspina, la "Historia de la Sociedad Humana". La expedición que diri-

6 Citado en Galera Gómez, Andrés: "La expedición Malaspina”, Sellés, Manuel; Peset, José Luis; Lafuente, Antonio (comps.): Carlos III y la ciencia de la Ilustración, Alianza, Madrid, 1989, págs. 372 y 373.

7 Calatayud, María de los Ángeles: Catálogo de las expediciones y viajes científicos españoles a América y Filipinas, siglos XVIII y XIX, CSIC, Editorial Madrid, Madrid, 1984. 
gió tan insigne explorador sería un buen ejemplo de ello, al que podríamos añadir otros muchos suficientemente conocidos. ${ }^{8}$

Uno de estos viajeros de la Ilustración, el marino y científico andaluz Antonio de Ulloa, miembro de la celebérrima expedición franco-española (1735-1744) enviada al virreinato del Perú para calcular el grado de esfericidad de la Tierra, denunció desde sus Noticias Americanas (1772) que tras el descubrimiento del Nuevo Continente no se hubiesen realizado suficientes indagaciones sobre su medio natural, ni tampoco sobre "las antigüedades, las costumbres y el carácter, genio e inclinaciones" de los indígenas. Según Ulloa, tales investigaciones serían de gran utilidad. Las primeras porque proporcionarían "documentos para el conocimiento del Mundo", mientras que las segundas sobre los "diversos Pueblos de la Tierra" que lo habitaban, ilustrando sus distintos "usos y costumbres", así como su grado de inclinación "a la mayor cultura y al adelantamiento de las luces naturales y de la razón”. Desde esta perspectiva, lo que denominó "memorias de la antigüedad", es decir, las antiguas producciones materiales de las poblaciones indígenas, adquirieron un gran valor ya que devenían "demostraciones verídicas de lo que fueron las gentes en los tiempos a que se refieren”. Por ellas se averiguaría "lo que alcanzaron, el modo en que se manejaron, su gobierno y economía; y a este respecto, lo que han adelantado o perdido, lo numeroso de su gentíos, la industria, el valor y las máximas de manejarse". ${ }^{9}$ No casualmente, de los veintidós capítulos que conformaban las Noticias, del XVII al XXI se dedicaron a las costumbres, creencias, saberes, lenguas y "antigüedades de los indios". ${ }^{10}$

Lo cierto es que desde el descubrimiento de América fueron muchos los cronistas españoles que describieron con curiosidad no sólo la desconocida naturaleza que se extendía ante sus ojos, sino también las sociedades,

8 Pino, Fermín del: "Los estudios etnográficos y etnológicos en la expedición Malaspina", Revista de Indias, n. ${ }^{\circ}$ 169-170, Madrid, 1982, págs. 393-465; Alcina, José: El descubrimiento científico de América, Anthropos, Barcelona, 1988.

9 Ulloa, Antonio de: Noticias Americanas: Entretenimientos phisicos-historicos sobre la América Meridional, y la Septentrional Oriental, Imprenta de F. Manuel de Mena, Madrid, 1772, Introducción, s.p.

10 Ulloa no tuvo demasiada buena opinión de las capacidades de los indígenas americanos ni de sus consecuciones en las ciencias o en las artes. Véanse, por ejemplo, sus opiniones al respecto vertidas en el capítulo XI del Libro VI de su Relación Histórica del Viage a la América Meridional (1748), dedicado a los "monumentos en la jurisdicción de Quito de los antiguos Indios", o en el capítulo XX de las citadas Noticias. Francisco de Solano, en diversos estudios, ha desmenuzado la personalidad y la obra de Ulloa. Por ejemplo, Solano, Francisco de: La pasión de reformar. Antonio de Ulloa, marino y científico, 1716-1795, Universidad de Cádiz, Cádiz, 1999. 
las costumbres y las producciones indígenas. ${ }^{11}$ No obstante, el anhelo de trazar de la manera más precisa posible aquel "gran mapa de la humanidad" al que se refirió Burke, propició un interés renovado en el siglo XVIII por la América indígena y, entre otros aspectos, por su patrimonio material y sus antigüedades. El testimonio de Ulloa al respecto es elocuente. Pero en España, subrayémoslo, este interés adquirió una especial importancia por distintas razones de índole política y de prestigio que fueron más allá de la puramente enciclopédica o la ya apuntada de legitimización de la superioridad cultural de la Metrópoli y, por tanto, de su expansión colonial.

\section{España y las antigüedades americanas en el Siglo de las Luces}

De todos es sabido que la colonización americana por parte de los españoles fue presentada por muchos escritores europeos, entre ellos algunos insignes representantes de la Ilustración, con las más negras tintas posibles. Pusieron el acento en la sanguinaria crueldad de los conquistadores y en la pésima gestión de los virreyes posteriores a ellos, únicamente interesados en extraer todo el oro y la plata posible de las entrañas del Nuevo Continente. Tal caracterización de la colonización de América era, sin duda, uno de los puntales de la ominosa Leyenda Negra de España. Todavía en pleno siglo XIX, en el discurso preliminar de las Antiquités Mexicaines. Relation des trois expeditions du colonel Dupaix, Ordóñez en 1805, 1806

11 No hay duda de que desde la llegada de los europeos a América, el Nuevo Continente fue una variable ineludible en la reflexión que aquéllos emprendieron sobre el mundo y los hombres. Incluso tenemos documentados los primeros envíos de objetos americanos, tanto naturales (plantas, minerales, animales) como artificiales (joyas, trajes, ídolos, armas) a la Metrópoli entre los siglos XVI y XVII. Véase: Bernal, Ignacio: A history of mexican archaeology. The vanished civilizations of Middle America, Thames and Hudson, Londres, 1980; Morán, Miguel y Checa, Fernando: El coleccionismo en España. De la cámara de maravillas a la galería de pinturas, Cátedra, Madrid, 1985, págs. 129-138; La imagen del indio en la Europa Moderna, CSIC - Fundación Europea de la Ciencia - Escuela de Estudios Hispano-Americanos, Madrid, 1990; Pino, Fermín del: "El capítulo de antigüedades en las historias naturales", en Historiografía de la Arqueología y de la Historia Antigua en España (s. XVIIIXIX), ICRBC, Madrid, 1991, págs. 33-38; Cabello, Paz: "La Corona y el coleccionismo americano", Reales Sitios, n. ${ }^{\circ} 112$, Madrid, 1992, págs. 37-44; Cabello, Paz: "Los inventarios de objetos incas pertenecientes a Carlos V: estudio de la colección, traducción y trascripción de documentos", Anales del Museo de América, n. ${ }^{2}$, Madrid, 1994, págs. 33-61; López Rodríguez, José Ramón: "Sevilla, el nacimiento de los museos, América y la botánica", en Gascó, Fernando y Beltrán, José (eds.): Historiografía de la arqueología e historia antigua en Andalucía, Junta de Andalucía, Sevilla, 1995, págs. 75-97; Alcina, José: Arqueólogos o Anticuarios. Historia antigua de la Arqueología en la América Española, Serbal, Madrid, 1995, págs. 43-56; Checa, Fernando (dir.): La materia de los sueños, Junta de Castilla y León - Sociedad Estatal de Conmemoraciones, Valladolid, 2006. 
et 1807, par le Roy Charles IV, pour la recherche des antiquités du pays... avec les dessins de Castañeda (1844), Charles Farcy arremetía contra España por haber enviado al Nuevo Continente soldados ambiciosos y curas obsesionados con la idolatría, y no científicos que observasen su medio natural o estudiosos de sus antigüedades. Lo curioso de estas afirmaciones no son tanto los siniestros prejuicios de los que hizo gala el francés Farcy, sino que los espetase como preludio a la publicación de la descripción y los dibujos de las antigüedades mexicanas que llevaron a cabo el capitán de origen flamenco Guillermo Dupaix y el dibujante nacido en Toluca Luciano Castañeda, durante tres expediciones realizadas entre los años 1805 y 1808 por todo el territorio de Nueva España y que fueron sufragadas por Carlos IV. ${ }^{12}$ Y la de Dupaix-Castañeda no fue la única expedición de esta naturaleza. El propio Farcy hizo referencia a la otra gran expedición ilustrada destinada al mejor conocimiento de las ruinas precolombinas, la del capitán de artillería Antonio del Río a Palenque, que se desarrolló en 1787, tras las primeras investigaciones del yacimiento a cargo del teniente de alcalde José Antonio Calderón (1784) y del arquitecto Antonio Bernasconi (1785). Advirtamos que la campaña de Del Río fue, de igual modo, auspiciada por la Corona española. ${ }^{13}$

Estas expediciones, que a pesar de sus limitaciones han sido calificadas por prestigiosos investigadores como las primeras exploraciones arqueológicas de tipo científico llevadas a cabo en América, demuestran con elocuencia el interés del gobierno español por conocer las antigüedades prehispánicas. Por un lado, era consciente que tener acceso a una inédi-

12 Dupaix, Guillermo: Expediciones acerca de los antiguos monumentos de la Nueva España, 1805-1808, Introducción y notas a cargo de José Alcina. José Porrúa Turanzas, Madrid, 1969.

13 Sobre las expediciones ilustradas a Palenque, ver: Cabello, Paz: Política investigadora de la época de Carlos III en el área maya. Según documentación de Calderón, Bernasconi, Del Río y otros, Ediciones de la Torre, Madrid, 1992; Ballesteros, Manuel: Estampas de Palenque, Testimonio, Madrid, 1993; Alcina, Arqueólogos o Anticuarios, págs. 83-110; Cañizares-Esguerra, Jorge: How to write the history of the New World. Histories, Epistemologies and Identities in the Eighteenth-Century Atlantic World, Stanford University Press, Stanford, 2001, págs. 321-345. Mientras un profundo conocedor de la arqueología precolombina como José Alcina juzgó ejemplares por su extensión y rigurosidad las observaciones de Dupaix (Expediciones), las excavaciones de Del Río en el yacimiento maya de Palenque han sido calificadas por otra destacada especialista, Paz Cabello, como "las primeras excavaciones científicas en América" (Cabello, "La Corona...", pág. 42). José Alcina ha reivindicado en distintas publicaciones el decisivo papel que tuvieron las aportaciones de los exploradores y viajeros españoles en América a la incipiente arqueología, si bien han sido sistemáticamente ignoradas por la bibliografía anglosajona: "Las más antiguas excavaciones estratigráficas en América”, en Arqueología, historia y antropología. In memoriam José Luis Lorenzo, Instituto Nacional de Antropología e Historia, México, 2000, págs. 69-77; "La arqueología americana en tiempos de Carlos III”, Reales Sitios, n. ${ }^{\circ}$ 148, Madrid, 2001, págs. 32-40. 
ta pero decisiva información sobre las culturas precolombinas supondría un privilegiado control sobre la propia historia de América. No es casual que Juan Bautista Muñoz, cronista de Indias desde 1779 y enfrascado en la redacción, por orden del rey, de una historia oficial de América que contrarrestase las opiniones vertidas en la History of America (1777) de William Robertson, muy crítica con la conquista española, apoyase las exploraciones anticuarias a Palenque, siguiese sus resultados y pensase utilizarlos en su crónica. Desgraciadamente, dicha crónica quedó inconclusa a su muerte y sólo se llegó a publicar un tomo. ${ }^{14}$ Por otro lado, a nadie se le escapaba que, en pleno Siglo de las Luces, la generosa protección de expediciones científicas dirigidas a "rasgar los velos" de la ignorancia, aumentaría el prestigio del gobierno borbónico, presentándolo como uno moderno e ilustrado. ${ }^{15}$ En un momento en el que no eran pocas las voces que dentro y fuera del país dudaban del nivel cultural e incluso de las contribuciones de España a la civilización, cualquier apoyo en este sentido sería bien recibido. Los borbones españoles y sus ministros, obsesionados por aparecer como los regeneradores de la nación, contaban, además, con un privilegiado escaparate para mostrar al mundo los hallazgos que se realizasen en América. Nos referimos al Real Gabinete de Historia Natural, abierto al público en el palacio Goyeneche de la madrileña calle de Alcalá en 1776. ${ }^{16}$

Desde sus inicios formaron parte de la colección del Real Gabinete de Madrid tanto objetos de los tres reinos naturales, como antigüedades, obras de arte y manufacturas de procedencia exótica, acogiendo bajo su techo tanto las maravillas que ofrecía la naturaleza como las producidas por el hombre. Este carácter heterogéneo se mantuvo en los años siguientes a su apertura en 1776. Es más, en parte fruto de las peticiones expresas de sus responsables, a lo largo del último tercio del siglo XVIII fueron llegando al

14 Cañizares-Esguerra, How to write, 2001, págs. 170-202; Bas, Nicolás: El cosmógrafo e historiador Juan Bautista Muñoz (1745-1799), Universitat de València, Valencia, 2002; Mestre, Antonio: Apología y crítica de España en el siglo XVIII, Marcial Pons, Madrid, 2003.

15 Pino, Fermín del: "Utilidad y honor nacional en la política científica ilustrada", en Fernández Pérez, Joaquín y González Tascón, Ignacio: Ciencia, técnica y Estado en la España ilustrada, Ministerio de Educación y Ciencia - Sociedad Española de Historia de las Ciencias, Madrid, 1990, págs. 31-43; Bourguet, "El explorador”, pág. 275.

16 Calatayud, $\mathrm{M}^{\mathrm{a}}$ de los Ángeles: Catálogo de documentos del Real Gabinete de Historia Natural (1752-1786), CSIC, Madrid, 1987; Calatayud, $\mathrm{M}^{\mathrm{a}}$ de los Ángeles: "El Real Gabinete de Historia Natural de Madrid”, en Sellés, Manuel; Peset, José Luis; Lafuente, Antonio (comps.): Carlos III y la ciencia de la Ilustración; Lucena, Manuel: "La imagen de América en la España ilustrada. De la ambigüedad libresca al Real Gabinete de Historia Natural", Reales Sitios, n. ${ }^{\circ}$ 148, 2001, Madrid, págs. 40-50; Pimentel, Testigos del mundo. 
Real Gabinete piezas arqueológicas y etnográficas enviadas por las autoridades coloniales y por las expediciones científicas que recorrieron América. Destaquemos, entre otros posibles ejemplos, la famosa Estela de Madrid, un relieve maya del periodo clásico tardío (600-900 d.C.) remitido a la corte por Antonio del Río junto a otras piezas que halló en Palenque, "como muestra del grado a que llegaron los antiguos del País en esta parte de escultura". ${ }^{17}$ Con ello, Del Río cumplía con las instrucciones para surtir al Real Gabinete redactadas por el ecuatoriano Pedro Franco Dávila, su primer director, y dirigidas a las distintas autoridades de los territorios de la monarquía. Si bien demandó preferentemente objetos naturales, solicitó de igual modo "algunas curiosidades de arte, como son ídolos, pinturas, diseños, máquinas, armas, instrumentos, vestidos, muebles y otras cosas que merecen la atención particular de los pueblos". ${ }^{18}$ Algunos años después, Vicente del Seixo, en su Compendio de Observaciones que forman el plano de un viage político que debe hacerse dentro y fuera del Reyno (1796), tras detallar el modo de preparar "las producciones naturales" que los viajeros pagados por el gobierno debían reunir con destino al Real Gabinete durante sus periplos allende, recordó que dichos viajeros "no sólo deberán enviar todas las cosas naturales sino también las artificiales dignas de notarse, como algunas manufacturas prodigiosas o aquellas que denoten la industria o manifiesten el gusto del País, como Vestidos, Armas, Instrumentos, etc.". ${ }^{19}$

Sabemos por distintos testimonios que las manufacturas exóticas, y en especial las americanas, que se llegaron a mostrar al público en el Real Gabinete llamaron la atención de sus visitantes. Viajeros británicos como George D. Whittington o Robert Semple manifestaron su admiración por "the curiosities from South America" que se exhibían en el museo madrileño. ${ }^{20}$ De hecho, la fama de estos objetos llegó a traspasar las fronteras del país, encontrando incluso un eco en la polémica History of America (1777) de William Robertson, quien se refirió al "magnífico gabinete de curiosida-

17 Citado en Cabello, Política investigadora, pág. 140.

18 Las instrucciones de Dávila y Ulloa se citan en: Cabello, Paz: Coleccionismo americano indígena en la España del siglo XVIII, Ediciones de Cultura Hispánica, Madrid, 1989, pág. 62.

19 Seixo, Vicente del: Compendio de Observaciones que forman el plano de un viage político que debe hacerse dentro y fuera del Reyno en que nacemos, y luego por la Europa y demás partes de la tierra, Imprenta de Pantaleón Aznar, Madrid, 1796, pág. 277.

20 Whittington, George Dowing: Travels through Spain and part of Portugal, T. Gillet, Londres, 1808, t. II, págs. 12-13; Semple, Robert: Observations on a journey through Spain and Italy to Naples; and thence to Smyrna and Constantinople, C. and R. Baldwin, Londres, 1807, t. I, pág. 78. 
des naturales y artificiales que acaba de abrir el rey Católico”. No había podido verlos personalmente porque nunca había estado en Madrid, mas le habían asegurado "que los ponderados esfuerzos del arte de los mexicanos son torpes representaciones de objetos comunes o imágenes de figuras humanas y de animales privadas enteramente de gracia y propiedad". ${ }^{21} \mathrm{Un}$ juicio sobre la calidad de las artes precolombinas que, como veremos, fue muy distinto del manifestado por los eruditos españoles y, sobre todo, por los criollos.

No hay duda de que la proyección del Real Gabinete de Historia Natural fue un fenómeno pretendido por las autoridades y por sus máximos responsables..$^{22}$ Se consiguió en parte ya que el Real Gabinete devino un hito ineludible para todos aquellos que se refirieron al Madrid borbónico. Es más, se consideró un símbolo de los cambios que se estaban llevado a cabo en las últimas décadas para poner a Madrid y al propio país a la altura de los tiempos. Y es que si en el siglo XVIII un gabinete de historia natural se consolidó como un equipamiento indispensable para una ciudad que se desease moderna, lo era todavía más para la capital del mayor imperio colonial contemporáneo. Desde su fundación, el gobierno español fue plenamente consciente del enorme potencial propagandístico del Real Gabinete. A través de sus colecciones no sólo se mostraría el poder de la Corona y sus inmensos territorios coloniales de las que procedían muchas de sus piezas, entre ellas las etnográficas y arqueológicas americanas, sino también su apertura a los saberes modernos y a la renovada ciencia ilustrada. No fueron pocos los que, confiados y esperanzados, saludaron la apertura del Real Gabinete de Historia Natural como un signo inequívoco de que el país iba a superar definitivamente su atraso científico y a situarse como un igual entre las naciones europeas más adelantadas, contribuyendo de manera activa a incrementar el conocimiento existente sobre el mundo y el hombre. Tales esperanzas fueron demasiado optimistas, aunque el Real Gabinete propició ciertos logros que no deben pasar inadvertidos. Sea como fuere, las fuertes tensiones de principios del siglo XIX y la progresi-

21 Clavijero, Francisco Javier: Historia Antigua de Megico: sacada de los mejores historiadores españoles y de los manuscritos, y de las pinturas antiguas de los indios, R. Ackermann, Londres, 1826, t. II, pág. 372.

22 Lafuente, Antonio y Pimentel, Juan: "La construcción de un espacio público para la ciencia: escrituras y escenarios en la Ilustración española", en Historia de la ciencia y de la técnica en la Corona de Castilla. Vol. IV. Siglo XVIII, Junta de Castilla y León, Salamanca, 2002, págs. 111-156; Lafuente, Antonio y Valverde, Nuria: Los mundos de la ciencia en la Ilustración española, Fundación Española para la Ciencia y la Tecnología, Madrid, 2003. 
va independencia de muchas de las colonias de Ultramar provocaron que el americanismo en España se detuviese en seco al poco de iniciarse el nuevo siglo. Tal fue así que dejaron de llegar nuevas piezas que enriqueciesen el Gabinete y que mostrasen tanto el poder de la Corona como la variedad del mundo y, en palabras de Malaspina, la "Historia de la Sociedad Humana", ${ }^{23}$

\section{Bellas Artes y civilización durante la Ilustración. El caso de la América precolombina}

Durante la época de la Ilustración no todas las iniciativas de estudio y que revelaban un interés por las antigüedades precolombinas tuvieron como punto de partida y llegada la Metrópoli. De hecho, algunas de las empresas más destacadas surgieron entre los criollos de las colonias. Si los trabajos de Antonio del Río o de Guillermo Dupaix, recordemos que sufragados por la Corona, no vieron la luz hasta bien entrado el siglo XIX y por iniciativa de ingleses y franceses, fueron los intelectuales ilustrados americanos los que publicaron, ya a finales del siglo XVIII, los primeros estudios sobre el patrimonio prehispánico. El trasfondo de estas empresas fue, una vez más, los debates generados en el seno de la Ilustración en torno al denominado mapa del mundo y de la humanidad. En especial al lugar de América en él. Destaquemos que en la delimitación del debate fueron fundamentales las tesis expuestas por europeos como el conde de Buffon o Cornelius de Pauw. Este último, por ejemplo, defendió desde sus celebérrimas Recherches philosophiques sur les américains (1768-1769) la debilidad y la escasez de la naturaleza americana y la inferioridad de los indígenas e incluso de los criollos. ${ }^{24} \mathrm{Ni}$ tan siquiera sus antiguos reinos le merecieron un respeto. Cuzco, la antigua capital del impero Inca, no fue, al juicio de Pauw, más que un amasijo de cabañas gobernada por un déspota. Sólo la llegada de los europeos, según el prusiano, había mejorado un poco las cosas y abierto un horizonte de esperanza.

23 La historia decimonónica del Real Gabinete de Historia Natural y el destino final de algunas de las piezas precolombinas de su colección ha sido estudiada por Cabello, Coleccionismo americano, 1989; Cabello, Paz: "De las antiguas colecciones americanas al actual Museo de América", Boletín de la Asociación Española de Archiveros, Bibliotecarios, Museólogos y Documentalistas, n. ${ }^{\circ}$ XLIV, Madrid, 1994, págs. 177-203.

24 Aun con dedicarles escasas referencias, Pauw demostró un absoluto desprecio por la arquitectura y por las manufacturas producidas por los pueblos precolombinos. Gerbi, Antonello: La disputa del nuevo mundo. Historia de una polémica 1750-1900, Fondo de Cultura Económica, México, 1960. 
Si no fueron pocos los europeos de uno y otro lado de los Pirineos que reaccionaron ante las opiniones de Pauw, Buffon y sus seguidores, resulta lógico que los propios americanos también emprendiesen su contestación al haberse puesto en duda de manera descarnada sus capacidades y la de sus lugares. Desde el actual Chile a los Estados Unidos, proliferaron los apologistas, sobre todo criollos, que vindicaron las posibilidades para el progreso del Nuevo Continente y de aquellos que lo habitaban. Incluso algunos de estos autores preconizaron que América acabaría ocupando el lugar de Europa. Si bien se utilizaron distintos argumentos, siendo habituales los que ponderaron la riqueza y la fertilidad de la naturaleza americana, esta polémica provocó que el patrimonio material en general y las Bellas Artes precolombinas en particular, adquiriesen un renovado interés al interpretarse como una prueba más de la potencialidad del Nuevo Continente.

No deberíamos olvidar que en el Mercurio Peruano, papel periódico de orientación regeneracionista publicado entre 1790 y 1795 gracias al apoyo de la Sociedad Económica de Amigos del País de Lima, se publicaron un par de artículos centrados en la vindicación de las artes incaicas con la intención de desbaratar las tesis de los que predicaban su barbarie. ${ }^{25}$ Pero fue en México, en el virreinato de Nueva España, donde vieron la luz estudios monográficos de antigüedades que, participando plenamente de los debates sobre América, dieron a conocer piezas y conjuntos monumentales desconocidos hasta la fecha. No hay duda, pues, que México, o al menos los mexicanos, que desarrollaron sus trabajos dentro o fuera su patria (no debemos olvidar la labor de los jesuitas expulsos), llevaron la voz cantante en el conjunto del Nuevo Continente a la hora de vindicar el patrimonio material y artístico prehispánico. ${ }^{26}$

25 Nos referimos al artículo titulado "Idea general de los monumentos del antiguo Perú e introducción a su estudio" (Mercurio Peruano, 17 de marzo, 1791, n. $\left.{ }^{\circ} 22\right)$, donde su autor, José Hipólito Unánue, destacó que "el reconocimiento de las obras que erigieron (los Incas) por magnificencia o por necesidad, ofrecen ciertamente una nueva luz capaz de esclarecer la oscuridad en que yace sumergida la parte histórica y civil de la Monarquía Peruana en todo el tiempo que precedió a su conquista". Es más, gracias al estudio a través de los restos materiales y de las antiguas crónicas de sus avances en la agricultura, la medicina, la astronomía, la arquitectura o la cerámica, Unánue afirmó que "se podrá conjeturar el grado de civilización a que ascendieron y aún la duración de su Imperio". Similares opiniones manifestó Pedro Nolasco Crespo en su "Carta sobre los monumentos antiguos de los peruanos" (Mercurio Peruano, 19 y 23 de agosto de 1792, n. ${ }^{\text {ss }} 170$ y 171), insistiendo en el desarrollo que testimoniaban los restos arquitectónicos — terrazas para el cultivo, palacios, murallas, etc.— que se conservaban de los Incas. Sobre el Mercurio, véase: Clement, Jean-Pierre: El Mercurio Peruano 1790-1795. Vol. I: Estudio, Iberoamericana, Madrid, 1997.

26 Natividad Gutiérrez examina las razones de este protagonismo de México en su artículo "Memoria indígena en el nacionalismo precursor de México y Perú" en Estudios Interdisciplinarios de América Latina y el Caribe, Vol. 1, n. ${ }^{\circ}$ 2, Tel Aviv, 1990. 
Francisco Clavijero, jesuita nacido en el estado de Veracruz, publicó entre 1780 y 1781 en Cesena (Italia) su magna Storia antica del México, una de las primeras historias modernas del México precolombino. Ya en su prólogo, Clavijero confesó que lo movía el deseo de "reponer en su esplendor a la verdad ofuscada por la turba increíble de escritores modernos sobre América". ${ }^{27}$ De hecho, la última parte de la Historia de Mégico se compuso de nueve disertaciones en las que se combatían frontalmente las opiniones que sobre este país, su naturaleza, su historia y sus antiguos habitantes había espetado el más conocido de esa "turba de escritores modernos", Cornelius de Pauw. Destaquemos que la sexta disertación se dedicó a la vindicación de la cultura de los antiguos mexicanos. Para Clavijero, era indudable que las grandes naciones americanas pretéritas presentaban costumbres "bárbaras y crueles" y que sus artes no habían llegado a su perfección. Mas se apresuró a advertir que así fueron "antiguamente muchas naciones de las que ahora son las más cultas de Europa y como son en la actualidad muchos pueblos de Asia, de África y de la Europa misma". Lo que resultaba intolerable era que cierta "turba" de escritores los tratasen como si hubiesen sido "caribes o iroqueses", como bárbaros que no vivían en sociedad, que no tenían ni leyes, ni jueces, ni superiores, que hasta ignoraban la "idea de la Divinidad" y que desconocían la agricultura y las demás artes, "no sólo las necesarias a la vida sino también las de deleite y lujo". ${ }^{28}$ Esa referencia a las Bellas Artes nos interesa especialmente ya que revela que en el estudio y la recuperación de las grandes naciones prehispánicas las artes "de deleite y lujo" tuvieron un papel. Tanto fue así que Clavijero dedicó varios capítulos de su obra a estas disciplinas. Defendió que los aztecas e incluso sus antecesores alcanzaron altas cotas en la arquitectura militar y civil, construyendo mucho y bien tal como podía comprobarse en los restos de las obras que todavía se conservaban y en aquellas que los españoles habían descrito en sus crónicas..$^{29}$ Para Clavijero sus innegables habilidades también se manifestaron en la escultura, sobre todo en

27 Clavijero, Historia Antigua de Megico, Prefacio, t. I, s.p. Sobre Clavijero véase: Ronan, Charles: Francisco Javier Clavijero, S.J. (1731-1787): figure of the Mexican Enlightenment, Institutum Historicum, S.I., Roma, 1977; Martínez, Alfonso (ed.): Francisco Xavier Clavigero en la Ilustración mexicana, 1731-1787, El Colegio de México, México, 1988.

28 Clavijero, Historia Antigua de Megico, t. I, pág. 348.

29 "Los mexicanos", según Clavijero, conocían la columna, el arco y la bóveda y "aunque no hayan tenido un gusto arquitectónico comparable al de los europeos, no es menos cierto que los españoles quedaron sorprendidos y admirados al ver los palacios reales de México" (Ibídem. t. II, pág. 366). 
la realizada en piedra ${ }^{30}$ En la pintura sus consecuciones fueron menores, quedándose lejos de la "perfección que admiramos en los buenos artistas de Europa" ${ }^{31}$, pero destacaron en la plumaria, en los tejidos y en la orfebrería. Alzando una queja que fue cada vez más habitual, Clavijero censuró la destrucción de antigüedades precolombinas por el excesivo celo del clero o la mera codicia de los buscadores de tesoros, instando a su conservación ya que en ellas se hallarían muchas claves de la historia de los mexicanos, así como testimonios de sus capacidades.

El criollo oriundo de Ozumba José Antonio Alzate Ramírez (17371799), una de las más destacadas personalidades intelectuales del México colonial, publicó a finales de 1791 como suplemento a la Gazeta de Literatura de México, periódico de carácter ilustrado del que fue su editor, una Descripción de Xochicalco. En ella, Alzate llevó a cabo una descripción detallada de los restos de la pirámide tolteca de Xochicalco y reflexionó sobre las técnicas utilizadas en su construcción y su posible utilidad. A pesar de la precisión y del gran sentido crítico con que se guió en todas estas cuestiones, Alzate persiguió una confesada intención apologética. Ya en la Gazeta del 9 de agosto de 1785, en la que anunció por vez primera su intención de publicar su Descripción, subrayó que Xochicalco era "una estupenda obra de Arquitectura, émula de las de Palmira y de las que se comprenden en lo que se entiende por antigua Roma". Desmentía por ello "varias aserciones falsas que han vertido, principalmente algunos Autores extranjeros" sobre las escasas capacidades de los "antiguos Indios". Y es que tales edificios demostraban, según este conocido sacerdote, los conocimientos mecánicos, ingenieriles y hasta astronómicos de los pueblos mesoamericanos. Destaquemos que Alzate, a través de la Gazeta y de otras de las muchas iniciativas literarias que impulsó, fue un franco defensor tanto de las aportaciones criollas como de las indígenas, denunciando la persecución a la que estos últimos habían estado sometidos desde su conquista. ${ }^{32}$

30 A pesar de no conocer el hierro o el acero supieron "expresar en sus estatuas todas las actitudes y posturas de que es capaz el cuerpo humano, observando exactamente las proporciones y haciendo cuando era preciso las labores más menudas y delicadas" (Ibídem. t. I, pág. 372).

31 Ibídem. t. II, pág. 363.

32 Peset, José Luis: Ciencia y Libertad: el papel del científico ante la Independencia americana, CSIC, Madrid, 1987; Periodismo científico en el siglo XVIII: José Antonio de Alzate y Ramírez, Universidad Autónoma Metropolitana, México, 2001; Canizares-Esguerra, Jorge: How to Write the History of the New World: Historiographies, Epistemologies, and Identities in the Eighteenth-Century Atlantic World, Stanford University Press, Stanford, 2001, págs. 284-286. 
Partiendo de la Descripción de Xochicalco y de otra descripción, aunque mucho más breve, de la pirámide de Tajín también aparecida en la Gazeta de México (12 de julio de 1785) y firmada igualmente por Alzate, el jesuita guanajuatense Pedro José Márquez (1741-1820) publicó en Roma, ciudad en la que residía tras la expulsión de su orden de los territorios de la Corona española, su Due antichi monumenti di architettura messicana (1804). Esta obra se centró, precisamente, en el análisis de Xochicalco y de Tajín. ${ }^{33}$ Ilustrada con estos grabados, que Alzate ya diera a la imprenta, el estudio de Márquez no sólo completó las noticias ofrecidas por su antecesor, sino que se atrevió a proponer una distinta interpretación de la función de dichas pirámides. Las motivaciones que Márquez arguyó como móvil de su obra, no otras que la vindicación de las antiguas naciones mexicanas a través de su arquitectura, no nos son desconocidas. Sorprende, si acaso, su publicación en Roma, uno de los epicentros de la historiografía artística de la Ilustración, aunque ya apuntamos como América devino un problema de primera magnitud entre la erudición del Viejo Continente. En la dedicatoria de su estudio, Márquez se refirió a los "no pocos eruditos de la cultísima Europa" que extendían "sus miras a uno y a otro mundo", no deseando "ser privados de ninguno de los conocimientos americanos". Aún de mayor interés es que Márquez presentara su publicación como una suerte de complemento a la Descripción histórica y cronológica de las dos piedras, que con ocasión del nuevo empedrado que se está formando en la plaza principal de México, se hallaron en ella el año de 1790 (1792) del físico mexicano Antonio de León y Gama (17351802). Si esta eruditísima obra se centraba en el análisis de las creencias religiosas y en los conocimientos astronómicos de los antiguos mexicanos a partir del estudio de dos piedras monumentales halladas recientemente en la ciudad de México, el famoso Calendario Azteca y la Coatlicue, Márquez presentó su Due antichi monumenti como una suerte de adición o suplemento al tratar sobre "algunas obras arquitectónicas de aquella gen-

33 Este interés de Pedro José Márquez por la arqueología y las Bellas Artes, manifiesto en su Due antichi monumenti, no fue aislado. De hecho, Márquez participó muy activamente del rico debate arquitectónico y anticuario que recorría la Roma de la Ilustración a través de distintas empresas. Véase: Rodríguez Ruiz, Delfín: "El orden dórico y la crisis del vitruvianismo a finales del siglo XVIII: la interpretación de Pedro José Márquez", Fragmentos, n. ${ }^{\text {os }}$ 8-9, Madrid, 1986, págs. 20-47; Del mismo autor: "De la Torre de Babel a Vitruvio: origen y significado de la arquitectura precolombina según Pedro José Márquez", Reales Sitios, n. ${ }^{\circ}$ 113, Madrid, 1992, págs. 42-56; Romani, Antonella: "Pedro José Márquez (1741-1820) e l'immagine del Messico antico nella sua opera sull'architettura precolombiana", Archivum Historicum Societatis Iesu, vol. LXVII, n. ${ }^{\circ}$ 133, Roma, 1998, págs. 131-161. 
te" ${ }^{34} \mathrm{Y}$ es que para él, ambos estudios desvelaban aspectos complementarios de la cultura desarrollada por los antiguos mexicanos.

Según propia confesión, también a Antonio de León, a la hora de emprender su Descripción histórica y cronológica del Calendario Azteca y de la Coatlicue, le movió el deseo de "manifestar al orbe literario parte de los grandes conocimientos que poseyeron los indios de esta América en las artes y ciencias en tiempo de su gentilidad". Curiosamente, tras esta afirmación, León señaló que las esculturas que estudiaría no sólo demostrarían los conocimientos astronómicos de los aztecas, aspecto central de su ensayo, sino también "el primor de los artífices que fabricaron sus originales; pues no habiendo conocido el hierro ni el acero, grababan con tanta perfección en las duras piedras las estatuas que representaban sus fingidos simulacros". ${ }^{35}$ Según León, esta razón era más que suficiente para conservar tanto el Calendario como la Coatlicue. De ahí que reprodujese con entusiasmo en el mismo prólogo de su obra, las cartas del virrey de Nueva España ordenando que se preservasen "por los escasos monumentos que nos quedan de aquellos tiempos, y por lo que pueda contribuir a ilustrarlos" ${ }^{36}$ De hecho, el Calendario y la Coatlicue fueron las primeras piezas prehispánicas de una colección pública que con los años crecería, aunque intermitentemente, y acabaría convirtiéndose en el Museo de Antropología de México, fundado en $1825 .{ }^{37}$

Las obras hasta aquí citadas demuestran, entre otros aspectos, que a la hora de analizar la historia de América y la de sus reinos, los eruditos ilustrados tuvieron en cuenta tanto las fuentes escritas como las materiales. Nos parece fundamental destacar, además, que para los estudiosos de la segunda mitad del siglo XVIII, incluso para Alonso de León a la hora de enfrentarse al Calendario Azteca y la Coatlicue, algunas de las "memorias de la antigüedad" ya no sólo tenían valor por su carácter documental, sino también por su factura o su calidad artística. En el relato de su ya citada expedición arqueológica por Nueva España entre 1805 y 1808, Guillermo

34 Márquez, Pedro José: Sobre lo bello en general y dos monumentos de arquitectura mexicana Tajín y Xochicalco, Estudio y edición a cargo de Justino Fernández. UNAM, México, 1972, pág. 129.

35 León y Gama, Antonio: Descripción histórica y cronológica de las dos piedras, que con ocasión del nuevo empedrado que se está formando en la plaza principal de México, se hallaron en ella el año de 1790, Impr. de Felipe de Zúñiga y Ontiveros, México, 1792, pág. 4. Sobre los intensos debates que generó este espléndido hallazgo, ver: Cañizares-Esguerra, How to write ..., 2001, págs. 269-299. 36 Ibídem, pág. 9.

37 Bernal, Ignacio: A History of Mexican Archaeology: The Vanished Civilizations of Middle America, Thames and Hudson, Londres, 1980. 
Dupaix se refirió en varios lugares al interés de los testimonios materiales antiguos ya que en ellos podían hallarse noticias sobre las más diversas creencias, ritos y hechos políticos o militares de los pueblos que los habían erigido. No obstante, la propia hechura y el estilo de dichos testimonios también era un dato a tener en cuenta en sí mismo, independientemente de su función o su iconografía, como reflejo del periodo histórico en el que habían sido realizados. El propio Dupaix lo demostraría en sus notas. Dupaix casi siempre manifestó un juicio positivo sobre las esculturas y los monumentos arquitectónicos precolombinos que pudo observar. Ante conjuntos como Mitlan, Palenque o incluso Xochicalco, su admiración fue mayúscula, no dudando en compararlos con los levantados por las antiguas civilizaciones mediterráneas. Para Dupaix, los pueblos prehispánicos "no solamente entendían de simetría en sus obras arquitectónicas, sino que la empleaban igualmente en la estatuaria". ${ }^{38}$ Es más, disculpó a sus pintores y escultores por las poco canónicas proporciones que utilizaban para realizar sus figuras, ya que, según él, no se debía tanto a su falta de habilidad como a una serie de "leyes políticas o religiosas establecidas en el imperio mexicano que obligaban a los artistas a expresar en las estatuas de sus dioses, una constante actitud y un mismo estilo o carácter semejante al antiguo Egipto... limitando de este modo el ingenio inventivo del artífice y consiguientemente el progreso de la escultura".$^{39} \mathrm{~A}$ pesar de tales presuntos obstáculos, Dupaix subrayó que la calidad alcanzada en éstas y en otras producciones ponía en evidencia a los que postulaban que América era incapaz de "parir o producir algo de ingenio humano". Tales monumentos cabía considerarlos "testigos dignos de la mayor fe" de la existencia de "unos imperios de mucha extensión y poder" ${ }^{40}$ De hecho, el diverso estilo que presentaban estos monumentos le permitió distinguir distintas naciones precolombinas: a los antiguos mexicanos (o aztecas), a los zapotecas y a los "palencanos" (o mayas). Si bien Dupaix creyó que un paciente análisis estilístico de todas las obras de cada "escuela" podría ayudar a determinar la espinosa cuestión del origen y la cronología de estos pueblos y su posible relación con emigraciones procedentes del Viejo Continente - una teoría muy extendida en el momento- la falta de pruebas concluyentes le llevó a abstenerse de dictaminar un juicio sobre la cuestión. Los límites de su aproximación a los monumentos artísticos eran evidentes, mas la factura de

38 Dupaix, Guillermo: Expediciones, pág. 56.

39 Ibídem, pág.87.

40 Ibídem, pág. 231. 
éstos ya se revelaba como un instrumento para datarlos, determinar su origen, vincularlos a un pueblo u otro y para juzgar sobre su cultura.

La identificación entre Bellas Artes y el estado cultural de una nación, en el trasfondo de los trabajos de Dupaix y de los otros eruditos citados en estas líneas, fue afirmada explícitamente por José Antonio Alzate al inicio de su Descripción de Xochicalco (1791). Según Alzate, "un edificio manifiesta el carácter y cultura de las gentes: porque es cierto que la civilización o barbarie se manifiestan por el progreso que las naciones hacen en las ciencias y artes". ${ }^{41}$ No hay duda de que tales afirmaciones se remiten de manera directa a ciertos debates abiertos contemporáneamente en Europa y que promovieron la consideración de las Bellas Artes como privilegiados testimonios de la cultura de una sociedad. Resulta revelador de la apertura de estos nuevos caminos que en una obra fundamental para el americanismo europeo como fueron las Vues des Cordillères, et monuments des peuples de l'Amerique (1810-1813), su autor, el alemán Alexander von Humboldt, se felicitase de la "revolution hereuse" que se había producido en las últimas décadas "dans la manière d'envisager la civilisation des peuples", despertándose el interés por las obras de arte de todos los pueblos del globo. Todo ello con el propósito de juzgar más adecuadamente sus respectivas sociedades y trazar con la mayor pertinencia aquel "gran mapa de la humanidad" perseguido por los ilustrados. No fue casual, pues, que él mismo ofreciese una serie de grabados y comentarios de ciertas antigüedades y monumentos precolombinos en sus enciclopédicas Vues, un intento de ofrecer un fresco lo más completo posible de América. ${ }^{42}$

Es indudable que esta renovada consideración de las Bellas Artes cabría ligarla a la profunda revolución historiográfica que se produjo en el siglo XVIII y que ha sido considerada, en no pocas ocasiones, una de las aportaciones más destacadas del Siglo de las Luces. El nuevo paradigma de progreso sustentado en el movimiento ilustrado supuso el desplazamiento de valores más propios del mundo barroco y la aparición de un nuevo ámbito temático en la comprensión del pasado, que pretendió ahondar en los aspectos que se creyó que conllevaban un avance del conocimiento y de la civilización. Surgió así un inédito interés por el análisis de temas hasta la

41 Márquez, Sobre lo bello ..., pág. 193.

42 Humboldt, Alexander von: Vue des Cordillères, et monuments des peuples de l'Amerique, Chez M. Mare, Paris, 1816, t. I, pág. 12. La bibliografía sobre Humboldt es inmensa. Véase una recopilación actualizada en: Alejandro de Humboldt. Una nueva visión del mundo, Museo Nacional de Ciencias Naturales, Madrid, 2005. 
fecha no protagonistas o marginales en el discurso historiográfico, pero que ahora se consideraba que revelarían la situación de una sociedad y las causas de su decaimiento o desarrollo. En este renovado escenario las Bellas Artes encontraron un relativo fácil acomodo ya que presentaban una serie de rasgos que respondían al concepto de progreso propio de la Ilustración. Y es que para la mentalidad de las Luces, las producciones de las Bellas Artes eran parto del entendimiento, requerían buen gusto, así como una notable habilidad manual y técnica. La arquitectura, por ejemplo, demandaba un necesario desarrollo tecnológico y una precisa organización de la sociedad. No casualmente, aquellos que en estas fechas se refirieron con admiración a los monumentos precolombinos, tanto a los andinos como a los centroamericanos, destacaron la capacidad de sus responsables para levantar sus muros a partir de enormes bloques de piedra bien tallados y mejor conjuntados. Si para los ilustrados, las artes mecánicas y sobre todo las nobles eran el producto del entendimiento y de la progresiva decantación de experiencias, estas producciones cabían considerarse el resultado de formas de civilización avanzadas. Para Dupaix, una de las pruebas de la "remota antigüedad" de las obras precolombinas "es haber llegado en ellas a un grado magistral, pues la suma lentitud con que se propagan las artes y ciencias sin auxilio conocido requieren una serie de muchos siglos". ${ }^{43}$ En sus respectivas descripciones de las pirámides de Tajín y Xochicalco, Alzate y Márquez fueron un poco más allá, aunque respetando las coordenadas dadas, al poner de relieve el complejo pensamiento simbólico que encarnaban estos monumentos. Es más, en la necesaria organización de una gran "multitud" de trabajadores que requería una obra como Xochicalco, se reconocía, según Alzate, "la legislación de un monarca que comanda a tantos vasallos y a quien ellos obedecen con sumisión. Pues esto es lo que demuestra ser una nación civilizada", ${ }^{44}$

Pero tales vindicaciones de las artes precolombinas tuvieron claros límites. Ni siquiera aquellos que elogiaron con apasionamiento las producciones americanas se atrevieron a equipararlas en plano de igualdad con las que seguían la gramática clásica y se consideraban paradigma de las artes, es decir, con las producidas en la Atenas de Pericles, la Roma de León X o el París de Luis XIV. Y es que la reivindicación del patrimonio artístico prehispánico no fue acompañada de una revolución en la comprensión de lo bello, concepto que continuó definiéndose desde los principios del clasicismo. De

43 Dupaix, Expediciones, pág. 224.

44 Márquez, Sobre lo bello ..., pág. 206. 
todos modos, sí revela que el debate en el seno del clasicismo era mucho más rico de lo que a veces se ha supuesto, dando lugar incluso a sendas que con el tiempo llevarían a su propia disolución como lenguaje normativo. Sea como fuere, resulta interesante comprobar que aquellos que desearon subrayar el valor de los monumentos precolombinos utilizaron comparaciones con culturas artísticas consolidadas de la antigüedad para demostrar que sus soluciones no eran el producto de unas sociedades bárbaras y primitivas. Así, Guillermo Dupaix, quien ya vimos que equiparó ciertos conjuntos monumentales prehispánicos a los egipcios, cartagineses y a algunos griegos y romanos, alabó la adopción de pirámides por parte de los "Indios Mexicanos" para erigir sus templos. Según este autor, los antiguos mexicanos "manifestaron en esta elección un gusto ciertamente nada despreciable y digno de la mejor religión", ya que la forma piramidal "sea por su ancianidad, solidez, regularidad puramente geométrica y su alta planta... le dan un aspecto serio y majestuoso que llena y satisface el entendimiento". Las mismas pirámides mexicanas llevaron a Pedro José Márquez a establecer equiparaciones entre la arquitectura prehispánica y la egipcia y la bíblica; incluso Márquez destacó el carácter vitruviano de algunas de las soluciones adoptadas por los "antiguos mexicanos". ${ }^{45}$ Todo ello sugería un posible acerbo común ya que, como dijimos, el origen de los pueblos americanos a partir de una emigración desde el Viejo Continente era una tesis muy difundida en este momento. En todo caso, las artes precolombinas al mostrar puntos de contacto con las desarrolladas en la antigüedad mediterránea o, en su defecto, con el propio hecho artístico y arquitectónico, salían dignificadas, dotadas de unas fuertes raíces que imposibilitaba que fuesen arrastradas junto a las producciones de pueblos en un presunto estado de civilización muy primario, tal como aquellos "caribes o iroqueses" a los que se refirió Clavijero y con los que algunos deseaban equipararlos. Es más, su puesta en paralelo con las producciones de las culturas pretéritas del Viejo Continente les dotaba de un lugar en dicha categoría, la de la antigüedad, que les confería un indudable prestigio. Alzate subrayó que "los galos o germanos", los pueblos antiguos del centro de Europa, no podían contar en su haber con obras como la pirámide de Xochicalco o la de Tajín si bien sus descendientes actuales se permitían acusar a la "antigua Nación Mexicana de poco numerosa, ignorante y poco civilizada". ${ }^{46}$

45 Rodríguez Ruiz, Delfín: “De la Torre de Babel...”, pags. 41-56.

46 Márquez, Sobre lo bello..., pág. 205, nota 2. 
Resulta revelador como Pedro José Márquez caracterizó la arquitectura precolombina en una historia de la arquitectura universal que incluyó en sus monumentales Apuntamientos por orden alfabético pertenecientes a la arquitectura, una obra enciclopédica que, desgraciadamente, no llegó nunca a publicarse. Para el erudito jesuita, los fundadores de los pueblos americanos partieron en fecha imprecisa de alguna de las regiones del Viejo Mundo, bien del Asia oriental o bien del África occidental. No obstante, en su emigración difícilmente podrían haber llevado consigo "los inventos de los griegos o de los egipcios", precisados como estuvieron a su llegada, según Márquez, a sobrevivir en un territorio virgen, perdiéndose rápidamente la memoria de lo visto y conocido en sus tierras de origen. De ahí su conclusión: las culturas surgidas en América eran "del todo nuevas". Según Márquez, este hecho era fundamental para valorar justamente el estado de sus conocimientos, el de sus artes y, por consiguiente, el de su arquitectura cuando llegaron los españoles a finales del siglo XV. No había la menor duda de que "las obras que allí se hicieron (en Perú y México), tomadas en general, no son comparables con las griegas, pero no por eso dejan de ser admirables y dignas de contarse entre las producciones de este arte" ya que "los dos imperios de la América contaban con pocos siglos de cultura; y en poco tiempo llevaron las artes a un grado de perfección no indiferente". Se preguntó seguidamente: "¿que hubieran hecho si su cultura hubiera comenzado cuando la de los Egipcios, y si hubieran tenido comercio con los asirios o con los griegos?". ${ }^{47}$ Las consecuciones y, sobre todo, la potencialidad de América y de los americanos resultaban incuestionables. Pero tal potencialidad no sólo se manifestaba en los monumentos prehispánicos. Al final de su escrito Márquez trazó la que cabría considerar una de las primeras historias del arte colonial en América. ${ }^{48}$ En ella se congratulaba de que gracias a la llegada de los españoles al Nuevo Continente, los americanos, por fin, habían conocido la modélica gramática grecorromana, habiéndose levantado obras considerables en dicho estilo. Auguraba que en el próximo siglo, en el XIX, debido al enorme potencial de América y a los avances experimentados en las últimas décadas con la apertura de algunas acade-

47 Márquez, Pedro José: Apuntamientos por orden alfabético pertenecientes a la arquitectura donde se exponen varias doctrinas de M. Vitruvio Polion, Biblioteca Nacional, Mss. 2459, f. 180 r y $180 \mathrm{v}$. Referencias a esta obra y al inconcluso proyecto de su publicación en el siglo XIX en: Gutiérrez Haces, Juana: "La preparación de un diccionario: Los Apuntamientos... pertenecientes a la arquitectura del padre Pedro José Márquez", Anales del Instituto de Investigaciones Estéticas, Vol. XVI, n. ${ }^{\circ}$ 65, México, 1994, págs. 77-91.

48 Rodríguez Ruiz, Delfín: "De la Torre de Babel...”, pág. 44. 
mias de Bellas Artes como la de San Carlos de México, América devendría una nueva Atenas. Aunque su afirmación estuvo restringida al ámbito de las artes, cabría sumar a Márquez a aquellos que creyeron que el futuro pertenecía a América.

Una de las consecuencias más notables de esta vindicación del patrimonio precolombino es que dotó de un pasado de prestigio a las comunidades americanas y muy especialmente a la mexicana. Reforzó así el orgullo de pertenencia de los criollos y ayudó a vertebrar una emergente identidad propia, ajena a la Metrópoli. Es por ello que los autores y las iniciativas hasta aquí desgranadas, se han venido considerando como una manifestación de un incipiente sentimiento criollista, en la base del movimiento independentista que, partiendo de distintas bases y blandiendo diversos argumentos, condujo a gran parte de las colonias trasatlánticas a separarse de la Corona española en las primeras décadas del siglo XIX. No parece casual, pues, que el recién creado gobierno autónomo mexicano viese con buenos ojos la publicación en París de las ya citadas Antiquités Mexicaines (1844), una obra que daba a conocer en Europa los resultados de las expediciones arqueológicas de Dupaix-Castañeda y de Del Río a través de una fastuosa edición. Incluso el general Santa Anna escribió unas apasionadas líneas para dicha publicación en la que se felicitaba, henchido de fervor patriótico, por la aparición de las Antiquités. Para el todopoderoso general, esta obra difundiría entre los europeos unos monumentos que afirmó eran tan dignos como los egipcios pero que hasta la fecha habían permanecido ignorados, demostrando que los antiguos pueblos americanos no eran ignorantes como algunos se habían atrevido a sostener.

\section{Últimas palabras. "An assemblage of Works of Arts"}

Como conclusión a los caminos hasta aquí trazados, digamos que entre la segunda mitad del siglo XVIII y los primeros años del XIX se llevaron a cabo una serie de trabajos que tuvieron como objetivo el mejor conocimiento del patrimonio material precolombino. Se realizaron excavaciones, se multiplicaron los descubrimientos de piezas y yacimientos, se promovió su conservación y exhibición pública, se dieron a conocer a través de publicaciones, elaborándose los primeros estudios exhaustivos y que se abrían a la modernidad. Si bien en estas décadas el protagonismo correspondió a los criollos y a los españoles, durante las primeras décadas del siglo XIX los 
europeos se sumaron con entusiasmo a este fenómeno. De hecho, en pocos años se pudo superar la total ignorancia de los eruditos europeos en relación al patrimonio precolombino y que había permitido juicios tan precipitados como los de Cornelius Pauw o William Robertson. Una elocuente prueba del escaso conocimiento que de la arquitectura precolombina tenían los europeos del llamado Siglo de las Luces la proporcionaría las Memorie degli architetti antichi e moderni (1768) del italiano Francesco Milizia. En este monumental compendio de la historia de la arquitectura, uno de los primeros de la historiografía artística moderna, las únicas referencias a América fueron unas líneas dedicadas a las construcciones de los incas en Cuzco basadas en crónicas y otros testimonios literarios similares. ${ }^{49}$

Pero nuestra intención no es ponderar vanas primacías, sino destacar que las antigüedades y una categoría en franca proyección, la de las Bellas Artes, se encontraban definiéndose como testimonio y reflejo de las sociedades que las produjeron $y$, por tanto, como un rasgo que determinaba su lugar en el mundo y en su historia.

Esta creciente curiosidad por conocer las antigüedades y las Bellas Artes precolombinas fue motivada, lo hemos visto, por múltiples razones. En parte, y sobre todo entre los eruditos europeos, fue alimentada por la creencia de que permitirían trazar con mayor precisión aquel gran fresco de la humanidad a través del cual desvelar el mecanismo íntimo de la civilización y su evolución. Así lo manifestaron autores como Charles Farcy, quien clamó que gracias a obras como las ya citadas Antiquités Mexicaines (1844), América por fin se inscribía, enriqueciéndola, en la historia del hombre. No casualmente, una de las principales preocupaciones de los europeos en relación a las artes precolombinas fue de orden digamos que "espacial", es decir, otorgarles un lugar en relación a las producciones artísticas de las otras grandes culturas del globo. En las mismas Antiquités Mexicaines el influyente escritor romántico Chauteaubriand propuso el envío a Mitlán y a Palenque de una expedición de estudio formada por ingleses conocedores de la arquitectura hindú y por algunos de los franceses que habían acompañado a Champollion a Egipto. Páginas después, en las mismas Antiquités, Alexandre Lenoir, el prestigioso director del reno-

49 El mismo Francesco Milizia tuvo palabras muy duras para la arquitectura precolombina en el primer tomo de su también muy influyente Dizionario delle Belle Arti del Disegno (1797), tildándola como inferior a la de los castores y considerando a sus responsables como estúpidos. Ver: Montijano García, Juan María: "Diversidad arquitectónica y tradición literaria en los apuntes sobre arquitectura inca y musulmana de Francesco Milicia. Primera aproximación", XIV Congreso Nacional de Historia del Arte, Las Palmas de Gran Canaria, 2006, t. I, págs. 375-381. 
vador Musée des Monuments Français, llevó a cabo un estudio comparativo entre las artes del antiguo México, las orientales y las egipcias. ${ }^{50}$

El intento de inscribir el arte precolombino en el gran mapa del mundo también se manifestó en las Vues des Cordillères, et monuments des peuples indigènes de l'Amerique (1810-1813) de Alexander von Humboldt. Ya en su prólogo Humboldt subrayó el enorme interés de comparar los monumentos de las diversas civilizaciones que se habían sucedido en una parte y otra del globo a lo largo de la historia. Según el alemán, de su puesta en común se deducirían sus distintas consecuciones, interpretándose no en un plano de igualdad sino como testigos de una presunta evolución intelectual de la propia humanidad. Y es que para Humboldt las producciones artísticas orientales o americanas — se refirió en varios lugares a la "grossièreté du style et de l'incorrection des contours dans les ouvrages des peuples de l'Amerique" - nunca alcanzaron la calidad y los elevados valores estéticos de las griegas o romanas, "dont la civilisation a été très-avancée". Estas diferencias entre los monumentos grecorromanos, tradición con la que Europa se identificaba, y los de otras civilizaciones del globo se remitían, pues, al distinto grado de desarrollo alcanzado por cada una de ellas. De ahí que el conocimiento de unos y otros ofreciesen un interés que Humboldt calificó de "psycologique" ya que "offrent à nos yeux le tableau de la marche uniforme et progressive de l'esperit humain. Les ouvrages des premiers habitans du Mexique tiennent le milieu entre ceux des peuples cites et les monumens antiques de l'Indostan. Quel spectacle imposant nous offre le génie de l'homme, parcourant l'espace qu'il y a depuis les tombeaux de Tinian et les statues de l'île de Pâques, jusqu'aux monumens du temple mexicain de Mitla; et depuis les idoles informes que renfermoit ce temple, jusqu'aux chefs-d'oeuvres du ciseau de Praxitèle et de Lysippe!". ${ }^{1}$

Tan reveladoras palabras devinieron imagen en una acuarela de James Stephanoff (1788-1874) titulada An assemblage of Works of Art, from the Earliest Period to the Time of Phydias (1845). Tal como desvela su mismo título, esta obra pretendía compendiar la progresiva evolución de las Bellas Artes, más formal que cronológica, desde sus más sencillas consecuciones

50 Sobre el Musée des Monuments Français, decisivo en la historia de los museos europeos, y el papel de su director, Alexandre Lenoir, ver: Vidler, Anthony: El espacio de la Ilustración, Madrid, Alianza, 1997; Haskell, Francis: La historia y sus imágenes, Alianza, Madrid, 1999.

51 Humboldt, Alexander von: Vue des Cordillères, et monuments des peuples de l'Amerique, par-avec 19 planches, dont plusieurs coloriées, Paris, 1816, t. I, pág. 47. 
hasta su culminación. Haciéndose eco de todos los prejuicios de la época pero también del nuevo conocimiento de las distintas culturas artísticas del globo, Stephanoff cartografió en su obra el arte mundial en su presunto recorrido de una menor a una mayor perfección. Colocó en la parte baja de la acuarela, es decir, en el primer estadio del largo camino, esculturas de Java, hindúes y prehispánicas (en concreto mayas). En la parte inmediatamente superior reprodujo de manera consecutiva esculturas y pinturas asirias, persas, egipcias, etruscas y de la Grecia arcaica. La culminación de todo ello eran, como no podía ser de otra manera, los relieves de Fidias para el Partenón de Atenas. La obra de Stephanoff manifiesta que las artes precolombinas a principios del XIX habían logrado consolidarse como un hito ineludible en el gran mapa mundial de la historia de las Bellas Artes, entendido como el de la evolución cultural del hombre. No obstante, este mapa se trazaba a partir de categorías etnocéntricas, encorsetando las producciones de muy distintas culturas en las rígidas estructuras con las que la Europa decimonónica definió no sólo lo artístico sino también la civilización. No estaría de más advertir que Stephanoff pintó la acuarela de la que hablamos dentro de una serie vinculada a las nuevas piezas llegadas desde distintas partes del mundo — en especial desde Grecia- al British Museum de Londres, depósito de excepción del mayor imperio colonial que se desarrollaría en el siglo XIX. ${ }^{52}$ En todo caso, sirva este último testimonio para comprobar que las Bellas Artes se habían definitivamente establecido en esas fechas como un instrumento para la comprensión del mundo y de su historia. El lugar otorgado al patrimonio monumental en ese gran mapa de la humanidad dependió de una determinada concepción de la civilización que estaba condicionada, como no podía ser de otra manera, por profundas posiciones ideológicas, siendo afectada a su vez, en una relación de dos direcciones y de influencia recíproca, por el conocimiento y la definición de distintas disciplinas entre las que se encontraba lo artístico. Y es que, sin duda, lo artístico también se definió a partir, entre otros parámetros, de cierto concepto de cultura y desarrollo. No es casual que, ya en el siglo XX, tal concepción de lo artístico periclitase paralelamente a dicha cartografía de la civilización que empezó a dibujarse en un ya lejano siglo XVIII.

Recibido el 15 de marzo de 2008 Aceptado el 4 de noviembre de 2008

52 Jenkins, I.: "James Stephanoff and the British Museum", Apollo, n. ${ }^{\circ}$ 121, Nueva York, 1985, págs. 179-181. 